\title{
Physical mechanisms of negative corona current pulse with secondary oscillation
}

\author{
V.I.Chyhin \\ National University "Lvivska Polytechnika", \\ 12 Bandery Str., 79013 Lviv, Ukraine \\ Received October 9, 2001, in final form January 21, 2002
}

\begin{abstract}
The detailed modelling of the negative corona current pulses including the secondary oscillation (SCO) has been realized, using the continuity differential equations for the fluxes of positive and negative ions and electrons, supplemented by the Poisson's equation for an electrical field in a quasione-dimensional space, as the basis for the numerical computation. The analysis of the basic plasma functions behaviour applicable to the pulsing corona in $\mathrm{Ar}+\mathrm{O}_{2}$ and $\mathrm{N}_{2}+\mathrm{O}_{2}$ mixtures in the concentration region of $\mathrm{O}_{2}$ from $2 \cdot 10^{-3} \%$ to $0.04 \%$ has been carried out and the physical mechanisms of the secondary current oscillation have been grounded for the first time. Moreover, an effect of the photoprocesses on the parameters of the strikingly different pulses in $\mathrm{Ar}+\mathrm{O}_{2}$ and $\mathrm{N}_{2}+\mathrm{O}_{2}$ mixtures is estimated for the first time. It has been determined that the SCO is caused by the field intensity oscillation in the antiphase in the surface region and in the end of the sheath. The SCO pulse can transfer into the full modes of the Trichel's pulse. Characteristics of the "precursor" and the "step" in the leading pulse front are determined by the dynamics of the volumetric charges in the sheath, whereas the SCO shape is determined by the variable flow of the positive ions to the cathode. In $\mathrm{N}_{2}+\mathrm{O}_{2}$ the ionization of $\mathrm{O}_{2}$ molecules by the $\mathrm{N}_{2}^{*}$ emitted photons leads to the adequate current rise. Pulse trailing part duration and current value are operated by the $\mathrm{O}_{2}^{-}$ions collisions with the $\mathrm{N}_{2}^{*}$ metastables. Such processes are slowed in $\mathrm{Ar}+\mathrm{O}_{2}$.
\end{abstract}

Key words: corona discharge, current pulse, pulse fine structure, secondary current oscillation, photo-processes, numerical modelling

PACS: 52.80.Hc, 52.35.-g, 52.65.-y, 51.50.+v

\section{Introduction}

The pulsing negative corona is the low current gas discharge arising between the point with a negative potential and the plane anode with the applied direct high voltage. Its pulses (discussed by Trichel for the first time [1]) are characterized by a 
relaxing shape, a strong periodicity and a temporal constancy of the parameters [27]. They have a complicated structure [8-13], specifically, a secondary high-frequency current oscillation (SCO) $[3-5,9,14-17]$. A detailed knowledge of the nature of the corona pulsation in the gas mixtures makes it possible to develop gas analyzer sensors [18] and gas separating devices [19]. However, nonequilibrium processes in this discharge are studied insufficiently. So far, there is not a consensus as to the formation mechanisms of the pulses, in particular regarding the SCO. The first qualitative explanation of the corona pulsations was grounded on a screening effect created by the positive ions in a vicinity of the cathode [1]. In the following publications the main screening role was referred to the negative ions [7]. The pulsation of the negative corona in a pure electropositive nitrogen is indicated in the work [20]. However, the authors have linked their calculation of the corona pulsation in the air only with "a carrying-out of negative ions from drift region" [21]. Such an approach does not allow to explain the dependence of the double pulse frequency on the admixture concentration $[2,4,5]$.

In our opinion, there are two main causes of the insufficient study of the nonequilibrium processes. The first one is the use of too high concentration of electronegative gas and the second one is an essential simplification of the modelling. The experiments connected with the direct study of the gas admixture effect on the pulse parameters were not carried out. The main focus was on an electronegative gas $[10,11]$ or a mixture of two gases with a high concentration of the electronegative gas $[12,20]$. The latter enhances the screening effect and, consequently, only some elements of the secondary pulse structure were registered [10-12]. But a more complicated secondary oscillation has been measured for the first time, when an extremely low concentration of oxygen in argon and in nitrogen was used $[2-5,9]$. The numerical model simplifications [21-23] have resulted in the inconsistent interpretation of the initial pulse rise $[11,16,17]$, since the secondary elements were qualitatively compared with the model results obtained under experimentally irrelevant conditions $[22,23]$. Besides, the corona SCO was not described [21]. Thus the recently registered secondary oscillations $[16,17]$ are explained phenomenologically by a "back and forth motion of the electric field" [22,24], a "turbulent beam-plasma interaction" $[6,16]$, or is referred to the "non-Trichel" one and it is recognized that its "mechanism ... has yet to be understood" [17].

The detailed modelling has allowed us to describe the main characteristics of the corona pulses with SCO for the first time $[2-5,9,14,15]$. In our opinion, a parallel experimental research and modelling of relatively simple systems is more prospective, particularly, using electropositive gases with different electronegative admixtures of variable concentration. In this work, the analysis of the basic plasma functions behaviour applicable to the pulsing negative corona is carried out and the physical mechanisms of the secondary current oscillation are grounded. Moreover, the effect of the photoprocesses on the parameters of strikingly different pulses in $\mathrm{Ar}+\mathrm{O}_{2}$ and $\mathrm{N}_{2}+\mathrm{O}_{2}$ mixtures in the concentration region from $2 \cdot 10^{-3 \%}$ to $0.04 \%$ is estimated for the first time. 

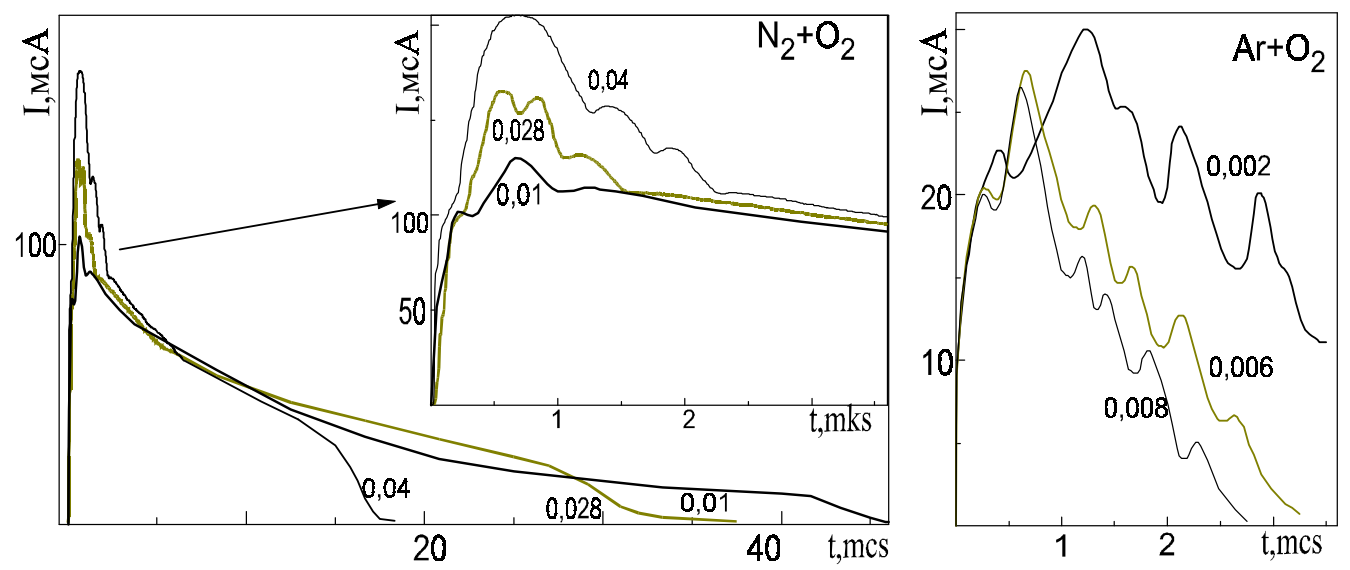

Figure 1. Corona current pulses oscillograms taken in gas mixture flows of nitrogen and oxygen as well as of argon and oxygen. The percentage of the oxygen is marked by the numbers. The point-plane anode distance is equal to $6 \mathrm{~mm}$ $\left(\mathrm{Ar}+\mathrm{O}_{2}\right)$ and to $12 \mathrm{~mm}\left(\mathrm{~N}_{2}+\mathrm{O}_{2}\right)$. The applied voltage is equal, accordingly, to $1420 \mathrm{~V}$ and to $2460 \mathrm{~V}$. The insertion represents the enlarged graphs top for $\mathrm{N}_{2}+\mathrm{O}_{2}$.

\section{Comparative characteristics of the measured pulses in $\mathrm{N}_{2}+\mathrm{O}_{2}$ and $\mathrm{Ar}+\mathrm{O}_{2}$ mixtures}

The investigations were carried out using the set-up, the scheme of which is described in detail in the works [2,3]. In figure 1 the typical current oscillograms, obtained in nitrogen and argon flows with various concentrations of oxygen, are presented. All the measured dependences $I(t)$ have the shape of the relaxing pulses with a complicated secondary structure. The sizes and the shapes of the pulses in $\mathrm{N}_{2}+\mathrm{O}_{2}$ and $\mathrm{Ar}+\mathrm{O}_{2}$ mixtures differ significantly. In $\mathrm{N}_{2}+\mathrm{O}_{2}$ the current increases sharply to the maximal value and then decreases by $10-50 \%$ in the narrow time interval (of the order of a microsecond), forming a separate peak, after which the curve falls down more slowly (of the order of dozens of microseconds. In $\mathrm{Ar}+\mathrm{O}_{2}$ mixture, the current averaged over the secondary oscillation falls down monotonously starting from the peak value. The current pulse duration in $\mathrm{N}_{2}+\mathrm{O}_{2}$ and $\mathrm{Ar}+\mathrm{O}_{2}$ mixtures reduces with an increase of the oxygen concentration. At the same time, in $\mathrm{N}_{2}+\mathrm{O}_{2}$, the maximal current value increases significantly. Simultaneously, in $\mathrm{Ar}+\mathrm{O}_{2}$, the peak height falls weakly. The secondary oscillation in $\mathrm{N}_{2}+\mathrm{O}_{2}$ mixture is located mainly in a peak region, while in $\mathrm{Ar}+\mathrm{O}_{2}$ it is located in the "tail" part of the pulse. The oxygen in both gas mixtures changes the shape and SCO parameters, specifically, their frequency and damping factor.

\section{Modelling the negative pulsing corona}

To introduce a kinetic model of the negative corona the following elementary processes were taken into account: an ionization, an excitation of $\mathrm{Ar}$ atoms and $\mathrm{N}_{2}$ 
molecules by electron collisions, an ionization by photons, an attachment of electrons to $\mathrm{O}_{2}$, their detachment from $\mathrm{O}_{2}^{-}$due to the collisions with $\mathrm{Ar}$ and $\mathrm{N}_{2}$ in the ground and in the excited states, a charge drift and a surface photo- and ion-electron emission. The basis of the numerical computation is the continuity differential equations for the fluxes of positive and negative ions and electrons, supplemented by the Poisson's equation for an electrical field in a quasi-one-dimensional space:

$$
\begin{aligned}
\frac{\partial n_{e}}{\partial t}+\operatorname{div}\left(w_{e} n_{e}\right) & =\alpha n_{e} w_{e}-\eta n_{e} w_{e}+k_{d} n_{n} n_{0}+k_{d m} n_{n} n_{m}+S_{f i} \\
\frac{\partial n_{p}}{\partial t}-\operatorname{div}\left(w_{p} n_{p}\right) & =\alpha n_{e} w_{e}+S_{f i} \\
\frac{\partial n_{n}}{\partial t}+\operatorname{div}\left(w_{n} n_{n}\right) & =\eta n_{e} w_{e}-k_{d} n_{n} n_{0}-k_{d m} n_{n} n_{m} \\
\frac{\partial n_{m}}{\partial t} & =\alpha_{m} n_{e} w_{e}-k_{d m} n_{m} n_{n}-k_{q} n_{m} n_{0} \\
\operatorname{div} E & =4 \pi e\left(n_{p}-n_{e}-n_{n}\right) .
\end{aligned}
$$

Here $n_{e}, n_{p}, n_{n}$ - the electron, positive and negative ions density, $w_{e}, w_{p}, w_{n}$ - their drift velocity, respectively, $\alpha, \eta$ and $k_{d}$ - the ionization, attachment and detachment coefficients for the main gas molecules of a density $n_{0}, S_{f i}$ - the charge source due to photoionization. The boundary conditions for positive and negative ions are selfevident; their number density is equal to zero at the anode and cathode, respectively. The boundary condition for electrons at the cathode $(x=0)$ is formulated in terms of the secondary ion and photon emission coefficients, $\gamma_{i}$ and $\gamma_{p h}$, accordingly:

$$
j_{e}(0, t)=\gamma_{i} j_{p}(0, t)
$$

where $j_{e}=n_{e} w_{e}$ and $j_{p}=n_{p} w_{p}$, and

$$
\begin{aligned}
n_{e}^{p h}(0, t)= & \frac{1}{w_{e}(0, t)} \cdot \frac{\gamma_{p h}}{\tau} \int_{0}^{t} \exp \left[-\left(t-t^{\prime}\right) / \tau\right] \\
& \times \int_{0}^{d} n_{e}\left(x, t^{\prime}\right)\left|w_{e}\left(x, t^{\prime}\right)\right| \alpha^{*}\left(x, t^{\prime}\right) \Omega(x) \exp (-\mu x) \mathrm{d} x \mathrm{~d} t .
\end{aligned}
$$

In the equation (7) $\mu$ is the coefficient of the photon absorption, $\tau$ - the lifetime of the exited state, $\alpha^{*}$ - the excitation coefficient. The quantity $\Omega(x)$ is the solid angle extended at the cathode by the charge at $x$. For the modelling details see $[2,22,25]$. In comparison with the previous model $[2,25]$ the additional equation (4) is included, describing the dynamics of the nitrogen metastable molecules density $n_{m}$. The coefficient $\alpha_{m}$ is their creation rate. The effect of the $\mathrm{N}_{2}^{*}$ metastables on the electron detachment from $\mathrm{O}_{2}^{-}$ions is given by $k_{d m}$, the quenching rate is described by $k_{q}$. The current in the external circle is determined using the second Kirchoff's law.

Because of very low current density of the negative corona it was assumed (as in all previous corona modellings $[2,4,20-23]$ ), that during the pulsation period the room gas temperature is kept in all discharge points. Under this condition, the coefficients of kinetic processes including the neutral particles are constant in time, and 
those related to the ionized particles are dependent only on the local field intensity [22]. The shape of the current channel was set, picking out two discharge gap regions: the cathode (generating) one as cylindrical and the drift one - as parabolic. A dependence of the current tube cross section $F$ on the positive ion density $n_{p}$ $\left(F \sim n_{p}^{2 / 3}\right)$ is suggested [2].

It was assumed, that the basic kinetic gas-discharge processes develop according to the next following schemes:

- a molecule and atom $\left(\mathrm{M}=\mathrm{N}_{2}\right.$, Ar) ionization by an electron impact

$$
e+\mathrm{M} \rightarrow \mathrm{M}^{+}+2 e
$$

- an attachment of electron due to a collision of three particles ( $\mathrm{M}$ is the third one, $\mathrm{N}_{2}$ or $\mathrm{Ar}$ )

$$
e+\mathrm{O}_{2}+\mathrm{M} \rightarrow \mathrm{O}_{2}^{-}+\mathrm{M}
$$

- an electron detachment from $\mathrm{O}_{2}^{-}$ion by a molecule impact $\left(\mathrm{M}=\mathrm{N}_{2}, \mathrm{Ar}\right)$

$$
\mathrm{O}_{2}^{-}+\mathrm{M} \rightarrow \mathrm{O}_{2}+\mathrm{M}+e
$$

- creating a metastable nitrogen or argon molecule $\left(\mathrm{M}^{*}=\mathrm{N}_{2}^{*}, \mathrm{Ar}^{*}\right)$

$$
e+\mathrm{M} \rightarrow \mathrm{M}^{*}+e
$$

- quenching a metastable molecule $\left(\mathrm{M}^{*}=\mathrm{N}_{2}^{*}, \mathrm{Ar}^{*}\right)$

$$
\mathrm{M}^{*}+\mathrm{M} \rightarrow 2 \mathrm{M}
$$

- an electron detachment from $\mathrm{O}_{2}^{-}$ion by a metastable molecule impact $\left(\mathrm{M}^{*}=\right.$ $\left.\mathrm{N}_{2}^{*}, \mathrm{Ar}^{*}\right)$

$$
\mathrm{O}_{2}^{-}+\mathrm{M}^{*} \rightarrow \mathrm{O}_{2}+\mathrm{M}+e
$$

The numerical data for the kinetic coefficients (the main data are entered in table 1) are determined in the following way.

The ionization processes of an atom and a molecule by an electron impact (8) in the wide energy region are described sufficiently in the literature $[7,26,27,42]$. In our computations, the nitrogen molecule ionization coefficients have been taken from the monograph [7] (table 5.1, Townsend formula $5.25 \alpha / p=A \exp (-B p / E)$, and the extrapolation of the experimental graphs figure 5.4-5.6). For a comparison there was also used a universal formula for the velocity constant of various reactions [26], $K=10^{-A-B /(E / n)} \mathrm{cm}^{3} / \mathrm{s}$. The coefficients of the argon atom ionization have been calculated using the formulas $\alpha / p=C \exp \left[-D(p / E)^{0.5}\right]$ and $\alpha / p=A_{1}(E / p) \exp \left(-B_{1} p / E\right)$ [7]. The last one takes into account the considerable inelastic losses of the electron energy, which are connected, first of all, with the excitation of the low energy levels of the argon atom. The $A_{1}$ and $B_{1}$ coefficients 
were calculated using a relation between the Townsend ionization coefficient, the ionization frequency and the ion drift velocity.

To model the process of three-body electron attachment with the oxygen molecule in the gas mixture of nitrogen-oxygen (9) there were used the coefficients given in [7]: $k_{a \mathrm{O}_{2}}$ - in the presence of the oxygen molecules only and $k_{a \mathrm{~N}_{2}}$ - in nitrogen molecules presence. The values $k_{a \mathrm{~N}_{2}}=0.16 \cdot 10^{-30} \mathrm{~cm}^{6} / \mathrm{s}$ and $k_{a \mathrm{O}_{2}}=2.5 \cdot 10^{-30} \mathrm{~cm}^{6} / \mathrm{s}$ coincide with the data in [43]. The attachment velocity dependence in pure $\mathrm{O}_{2}$ and $\mathrm{O}_{2}-\mathrm{N}_{2}$ mixtures on the middle electron energy measured in the region of $0.01-1 \mathrm{eV}$ [28], are in agreement with the data in [7] and [38] within the bounds of the multiplier 2. The data presented in work [42] are close to them as well. In our opinion, the attachment coefficient value $2 \cdot 10^{-33} \mathrm{~cm}^{6} / \mathrm{s}$ given in [27], is extremely understated. A field effect on the electron attachment velocity has been simulated using the formula represented in [22] for pure oxygen. Here the value $k_{a \mathrm{O}_{2}}$ is divided by the function $k_{a}=k_{a \mathrm{O}_{2}}\left[1+(E / g / n)^{1.5}\right]^{-1}$, where $g$ is the constant for a given gaseous mixture.

An attachment in $\mathrm{Ar}+\mathrm{O}_{2}$ mixture has been modelled, making use of the data [28] and extrapolating the graphs in figure 8.7.5 of a dependence of $k_{a}$ on the middle electron energy for pure $\mathrm{O}_{2}, \mathrm{O}_{2}$ in $\mathrm{N}_{2}$ and $\mathrm{O}_{2}$ in He. These functions come to an agreement with the separate data [43] for the process $\mathrm{O}_{2}+\mathrm{Ar}+e=\mathrm{O}_{2}^{-}+\mathrm{Ar}$.

In our opinion, comprehension of the electron separation from the negative oxygen ion in $\mathrm{N}_{2}+\mathrm{O}_{2}$ and $\mathrm{Ar}+\mathrm{O}_{2}$ mixtures according to the scheme (10) is still weak. The main problem attached to the study of this process is the effect of the competitive processes forming $\mathrm{O}^{-}, \mathrm{O}_{2}^{-}$and $\mathrm{O}_{3}^{-}$ions. A complete examination of the basic reactions connected with the oxygen negative ions has been done in the work [44]. As it appeared, in the dissociative attachment process, the atomic ions $\mathrm{O}^{-}$with the essential kinetic energy are generated. A separation of an electron from ions $\mathrm{O}^{-}$can take place, since only these ions relax to the steady energy states. During this energy relaxation, the detachment process competes with the charge exchange forming $\mathrm{O}_{2}^{-}$ or with the complicated formation of $\mathrm{O}_{3}^{-}$at the three bodies collision. That's why one has to estimate correctly a contribution into the channels of these negative ions development.

A velocity of the electron detachment from $\mathrm{O}_{2}^{-}$at an impact of the unexcited nitrogen molecule under the room temperature and with the middle ion energy value $E / n$ is low: "... at $k T=0.026 \mathrm{eV}$ a part of particles with the energy greater than $1 \mathrm{eV} \approx 40 k T$, is small ..." [7]. At the electric field intensity of the order of the $10^{4} \mathrm{~V} / \mathrm{cm}$ under the atmospheric pressure of nitrogen, the detachment velocity is of an order of $10^{-13} \mathrm{~cm}^{3} / \mathrm{s}$ [27]. Evidently, just due to a small effect of this process at the low ion energy, it was not taken into consideration in most of the modellings, as the negative corona $[8,22,23]$ and the positive corona $[29,45]$. However, taking into account that in the cathode region (the sheath playing a decisive role in forming the current pulse and its secondary structure [2]) the field intensity amounts to considerably higher values (in separate discharge stages - of the order of $10^{5}$ $10^{6} \mathrm{~V} / \mathrm{cm}$ ), in this work, as in [21], this electron detachment type was taken into account. The authors of [30] have investigated the electron separation from $\mathrm{O}_{2}^{-}$at the collision with $\mathrm{N}_{2}$ under extremely high ion energies $(>20 \mathrm{eV})$. A problem of our 
Table 1. Formulas and coefficient constants of kinetic processes

\begin{tabular}{|c|c|c|c|c|c|c|c|}
\hline \multicolumn{4}{|c|}{ Coefficient } & \multirow{2}{*}{\multicolumn{2}{|c|}{$\begin{array}{l}\text { Values of } \\
\text { constants }\end{array}$}} & \multirow{2}{*}{$\begin{array}{l}\text { Energy } \\
\text { range }\end{array}$} & \multirow[b]{2}{*}{ References } \\
\hline Process & \begin{tabular}{|l|} 
Symbol, \\
dimension
\end{tabular} & Particle & Formula & & & & \\
\hline \multirow[t]{2}{*}{ Ionization } & \multirow[t]{2}{*}{$\alpha, \mathrm{cm}^{-1}$} & $\mathrm{~N}_{2}$ & \multirow[t]{2}{*}{$\alpha / p=A \exp (-B p / E)$} & $\begin{array}{c}A \\
\\
8.8 \\
12.0 \\
\end{array}$ & $\begin{array}{c}B \\
\\
275 \\
342\end{array}$ & $\begin{array}{c}E / p \\
V /(\mathrm{cm} \cdot \text { tor }) \\
27-200 \\
200-600\end{array}$ & \multirow[t]{2}{*}[7]{} \\
\hline & & $\mathrm{Ar}$ & & \begin{tabular}{|l|}
0.01 \\
12.0 \\
\end{tabular} & $\begin{array}{c}31 \\
180\end{array}$ & $\begin{array}{c}5-22 \\
22-600\end{array}$ & \\
\hline \multirow[t]{2}{*}{ Attachment } & \multirow[t]{2}{*}{$k_{a}, \mathrm{~cm}^{6} / \mathrm{s}$} & $\mathrm{N}_{2}+\mathrm{O}_{2}$ & $k_{a \mathrm{~N}_{2}} \cdot n_{\mathrm{N}_{2}} \cdot n_{\mathrm{O}_{2}}+k_{a \mathrm{O}_{2}} \cdot n_{\mathrm{O}_{2}}^{2}$ & \multicolumn{2}{|c|}{$\begin{array}{l}k_{a \mathrm{~N}_{2}}=0.16 \cdot 10^{-30} \\
k_{a \mathrm{O}_{2}}=2.5 \cdot 10^{-30}\end{array}$} & $T=300 \mathrm{~K}$ & {$[7]$} \\
\hline & & $\mathrm{Ar}+\mathrm{O}_{2}$ & $k_{a \mathrm{Ar}} \cdot n_{\mathrm{Ar}} \cdot n_{\mathrm{O}_{2}}+k_{a \mathrm{O}_{2}} \cdot n_{\mathrm{O}_{2}}^{2}$ & \multicolumn{2}{|c|}{$k_{a \mathrm{Ar}}=0.1 \cdot 10^{-30}$} & $T=300 \mathrm{~K}$ & {$[28]$} \\
\hline \multirow[b]{2}{*}{ Detachment } & \multirow[b]{2}{*}{$k_{d}, \mathrm{~cm}^{3} / \mathrm{s}$} & $\mathrm{N}_{2}+\mathrm{O}_{2}^{-}$ & $\begin{array}{c}f(E / n) \\
\text { graphic \& tabular data }\end{array}$ & \multicolumn{2}{|c|}{$\begin{array}{l}2 \cdot 10^{-14} \\
3.8 \cdot 10^{-9}\end{array}$} & $\begin{array}{c}E / n=100 \mathrm{Td} \\
E / n=1000 \mathrm{Td}\end{array}$ & {$[27,42]$} \\
\hline & & $\mathrm{Ar}+\mathrm{O}_{2}^{-}$ & $\begin{array}{c}f(E / n), \\
\text { graphic data }\end{array}$ & \multicolumn{2}{|c|}{$\begin{array}{l}2.1 \cdot 10^{-13} \\
1.1 \cdot 10^{-9}\end{array}$} & $\begin{array}{c}E / n=150 \mathrm{Td} \\
E / n=3800 \mathrm{Td}\end{array}$ & {$[31]$} \\
\hline Excitation & $k_{m}, \mathrm{~cm}^{3} / \mathrm{s}$ & $\mathrm{N}_{2}\left(\mathrm{~A}^{3} \Sigma_{u}^{+}\right)$ & $10^{-A-B /(E / n)}$ & \multicolumn{2}{|c|}{$A=8.4 ; B=14$} & $\begin{array}{l}2<(E / n) \cdot 10^{16} \\
<30 \mathrm{~V} \cdot \mathrm{cm}^{2}\end{array}$ & {$[26,32]$} \\
\hline Quenching & $k_{q}, \mathrm{~cm}^{3} / \mathrm{s}$ & $\mathrm{N}_{2}\left(\mathrm{~A}^{3} \Sigma_{u}^{+}\right)$ & $\mathrm{N}_{2}\left(\mathrm{~A}^{3} \Sigma\right)+\mathrm{N}_{2} \rightarrow \mathrm{N}_{2}+\mathrm{N}_{2}$ & \multicolumn{2}{|c|}{$3.7 \cdot 10^{-16}$} & & $\overline{[27]}$ \\
\hline Detachment & $k_{d m}, \mathrm{~cm}^{3} / \mathrm{s}$ & $\mathrm{N}_{2}^{*}+\mathrm{O}_{2}^{-}$ & $\mathrm{O}_{2}^{-}+\mathrm{N}_{2}\left(\mathrm{~A}^{3} \Sigma\right) \rightarrow \mathrm{O}_{2}+\mathrm{N}_{2}+e$ & \multicolumn{2}{|c|}{$2.1 \cdot 10^{-9}$} & & {$[32]$} \\
\hline
\end{tabular}


work is partially identical to that considered in the works $[46,47]$, where the electron detachment effect on the statistic time delay of the negative corona current pulses in the air is discussed.

There seem to be no papers discussing the electron detachment in $\mathrm{O}_{2}^{-}+\mathrm{Ar}$ mixture. The cross sections of such process were measured at the collisions of the atomic ion $\mathrm{O}^{-}$with $\mathrm{Ar}$, and the ions $\mathrm{O}^{-}$and $\mathrm{O}_{2}^{-}$with helium [31]. In this connection, the electron detachment cross section in $\mathrm{O}_{2}^{-}+\mathrm{Ar}$ mixture was estimated, making use of the measured sections for $\mathrm{O}^{-}+\mathrm{Ar}$ and comparing the corresponding sections for $\mathrm{O}^{-}$and $\mathrm{O}_{2}^{-}$in helium [31]. Here, the differences in the detachment threshold energies and the transformation from laboratory to center-of-mass energies were taken into account.

Making use of the results of the investigations [7,26-29,32-39,42,43,45,48,49], there were analysed such possible photo-processes in the corona discharge, as the nitrogen molecule and the argon atom excitation, their quenching, the electron detachment from $\mathrm{O}_{2}^{-}$ion at the collision with the metastable particles $\mathrm{Ar}^{*}$ and $\mathrm{N}_{2}{ }^{*}$, as well as the ionization by photons emitted spontaneously by the excited molecules. Despite the fact that the radiation spectrum of the gas-discharge plasma is extremely wide [34,35,48], almost all experimental and numerical investigations of the nitrogen and the oxygen excitation processes (11) were associated with the determination of the corresponding parameters of their basic metastable states $[26,32,36,37]$. The kinetics of the low-energy $\mathrm{A}^{3} \Sigma_{u}^{+} \& \mathrm{~B}^{3} \Pi_{g}$ nitrogen metastables has been studied quite in detail, with a dividing of the separate oscillatory levels, specifically: in the streamer in the air [48], in $\mathrm{N}_{2}: \mathrm{O}_{2}=4: 1$ [26], and pure nitrogen [35], and gas mixture with various oxygen concentrations [37] discharges. One can find a large enough dispersion in the measured values of the quenching of the nitrogen and the argon metastable levels velocity constants (12) [26,38,49].

The detachment of an electron from $\mathrm{O}_{2}^{-}$ion at the collision with the metastable nitrogen molecule (13), the life time of which is considerable in comparison with the pulse duration, is some orders stronger than the detachment at the $\mathrm{O}_{2}^{-}$impacts with the unexcited $\mathrm{N}_{2}$ molecules $[7,26,27]$. It is shown in [26], that while the current density increases in the $\mathrm{N}_{2}: \mathrm{O}_{2}=4: 1$ discharge, the negative ions concentration decreases almost twice simultaneously with the proportional increase of the $\mathrm{N}_{2} \mathrm{~A}^{3} \Sigma_{u}^{+}$ metastable concentration. Under this condition, the $\mathrm{O}^{-}$ions are collapsed more effectively, specifically due to the growth of two orders of the excited oscillatory $\mathrm{N}_{2}$ state $(v=6)$ concentration. A destruction of the negative oxygen ions by the argon metastable atoms at the thermal energy is a weak process, having the cross section of the order of $1.6 \cdot 10^{-16} \mathrm{~cm}^{2}$ [38]. We have not found in the literature the velocity constant of the oxygen ion decay at its collision with the excited nitrogen and argon molecules at the energies higher than thermal, although such a process can be intensive [35].

It is believed that the photo-ionization of the air molecules is the essential process providing a generation of free electrons in the ionization front and determines the streamer propagation velocity $[29,33,45,50]$. However, the coefficients of transitions in the ultra-violet region, which can play an important role in forming the "fast" 
plasma kinetics, are almost absent in the literature. The photo-ionization processes of the air, the nitrogen and the oxygen by the integral radiation (of common photon energies) of the corona discharge have been experimentally studied in [39]. The empiric formula taken for the photoelectrons source (as a direct ionization of the oxygen molecules by the photons radiated from the nonresonance nitrogen molecules) was reduced to a more convenient form [33]. It was shown that the ionization of oxygen molecules is generally possible by photons with the wavelengths $\lambda \leqslant 1025 \AA$, and in the nitrogen discharge - in the region of $980 \AA \leqslant \lambda \leqslant 1025 \AA$ [33].

Making use of the research $[29,33]$ results, the photo-ionization term $S_{f i}$ (the velocity of photo-electron formation in the volume unit) for the nitrogen and oxygen mixture was calculated in the form of:

$$
S_{f i}(x)=p_{\mathrm{O}_{2}} \frac{\mathrm{d} x}{V(x)} \int_{x_{0}}^{x}\left|n_{e} \alpha w_{e}\right|_{x^{\prime}} \Psi\left(x^{\prime}, x\right) V\left(x^{\prime}\right) \mathrm{d} x^{\prime},
$$

where $\left|n_{e} \alpha w_{e}\right|_{x^{\prime}}$ is the amount of ionization cases in the volume unit in the point $x^{\prime}, V(x)$ is the volume element in the point $x, \mathrm{~d} x$ is the thickness of the photon absorption region, $p_{\mathrm{O}_{2}}$ is the $\mathrm{O}_{2}$ molecule partial pressure. The function $\Psi\left(x^{\prime}, x\right)$ determination [33] as a probability of the photo-electron appearance in the point $x$ caused by one ionization act in the point $x^{\prime}$, was used in the case of simplified computations:

$$
\Psi=\frac{\omega}{\alpha} \cdot \xi \cdot f
$$

where $\alpha$ is the first Townsend ionization coefficient, $\omega$-a number of the ionizing photons, which are generated by electrons in the length unit when the quenching is absent, $\xi$ - an effectiveness of the photo-ionization averaged in the spectrum of a radiation by the excited nitrogen molecules. The integral coefficient of the photoabsorption $f$ is as follows

$$
f(x)=\frac{\exp \left(-\kappa_{m n} p_{\mathrm{O}_{2}} \cdot x\right)-\exp \left(-\kappa_{m x} p_{\mathrm{O}_{2}} \cdot x\right)}{x \cdot \ln \left(\kappa_{m x} / \kappa_{m n}\right)},
$$

where $\kappa_{m x}=2, \kappa_{m n}=3.5 \cdot 10^{-2}\left(\mathrm{~cm}^{-1}(\mathrm{~mm} \mathrm{Hg})^{-1}\right)$ - the maximum and minimum cross sections of the absorption by the oxygen molecule of the photons emitted by the nitrogen molecules in the wavelength region of 980-1025 $\AA$. The parameter $\frac{\omega}{\alpha} \cdot \xi$ was taken from the work [33], where it is set in the form of the dependence on the reduced field intensity $E / p$. In the field value region from 30 to $200 \mathrm{~V} /(\mathrm{cm} \cdot \mathrm{mm}$ $\mathrm{Hg}$ ) the parameter $\frac{\omega}{\alpha} \cdot \xi$ changes faintly and non-monotonously within the limits of $0.05-0.12$.

Excitation of the high energy argon states in $\mathrm{Ar}+\mathrm{O}_{2}$ mixture by the electrons is an improbable process [7]. Here, the electron energy lowering takes place because of the essential losses for the low energy states excitation. Furthermore, the resonant argon base-line lengths 1065.6 and $1048.2 \AA$ at $3{ }^{1} \mathrm{~S}_{0}-3{ }^{3} \mathrm{P}_{1}$ and $3{ }^{1} \mathrm{~S}_{0}-3{ }^{1} \mathrm{P}_{1}$ transitions in the low temperature discharge [49] lie beyond the admissible bounds of the oxygen molecule ionization $\lambda \leqslant 1025 \AA[33]$. 
The drift velocity of the electrons, positive nitrogen and argon ions and negative oxygen ions $w_{e}, w_{p}, w_{n}$, just as in [2] were taken from works $[7,28,51]$.

In our modelling, some processes have been excluded from a consideration. For instance, the effect of the electron detachment from $\mathrm{O}_{2}^{-}$ion by the photon impact is low $[43,52]$ - at the energy of 1.9-2.7 eV, the $\mathrm{O}_{2}^{-}$decay section does not exceed $2 \cdot 10^{-18} \mathrm{~cm}^{2}[52]$. Taking into account the low concentrations of both particles $\left(\mathrm{O}_{2}^{-}\right.$ and photon) this process was neglected. The velocity of the dissociative electron attachment in $e+\mathrm{O}_{2} \rightarrow \mathrm{O}^{-}+\mathrm{O}[27,28,42,43]$ is known to be sufficiently high. However, taking into account that the electron detachment from the atomic ion $\mathrm{O}^{-}$is essentially higher as against the detachment from $\mathrm{O}_{2}^{-}$at middle energies $\left(10^{4}-\right.$ $10^{5} \mathrm{eV} / \mathrm{cm}$, typical for the corona cathode region) [28], and that such an attachment has caused changes of the air corona parameters no more than 5\% [21], this process was eliminated from consideration in our model, where the oxygen content is much too lower. On the same account, there were not considered the parameters such as the $\mathrm{O}_{2}$ ionization by electron impact, the direct two-body attachment $e+\mathrm{O}_{2} \rightarrow \mathrm{O}_{2}^{-}$and the excitation of $\mathrm{O}_{2} \mathrm{a}^{1} \Delta_{g}$ singlet metastables, as it was done in $[29,45]$. Since positive and negative ions are almost fully separated in space during the pulsation period of the negative corona, and since the passing time of electrons through the positive ions cloud (placed in a very narrow cathode sheath [2]) is short in comparison with the pulse duration, we have excluded the recombination electron-ion [27] and ion-ion $[22,23]$ processes from consideration. These processes have been considered in $[22,23]$ because the region of $\mathrm{O}_{2}^{+}$ions existence is greatly expanded in the depressed electric field of the corona with a large cathode area.

\section{Modelling results}

\subsection{Displacement current effect on the shape of the pulses}

Taking into account, that the main current pulse characteristics of the negative corona are determined by the cathode generating region $[2,4,5]$, there were used the formulas for the charge flow $I_{\mathrm{p}}$ and the displacement current $I_{\mathrm{dc}}[25,40]$, and the total current at a cathode $I_{\mathrm{k}}=I_{\mathrm{p}}+I_{\mathrm{dc}}$. At the sharp point of the cathode-needle, the $I_{\mathrm{dc}}$ current as the capacitance one, due to the cathode surface field change $\mathrm{d} E / \mathrm{d} t$, is significant in the pulse leading front only, when it approaches a value of the order of the ion current $I_{\mathrm{p}}$ (figure 2a). After the $I_{\mathrm{dc}}$ lowering, the increase of the total current slows down, forming a weak "step" in the front lines (figure 2a - "St", $t=1.91 \mathrm{mcs}$ ). At a considerable cathode area (the radius of $0.5 \mathrm{~cm}$, Morrow's data [22]), the displacement current at this point significantly exceeds the $I_{\mathrm{p}}$ current, forming the visible curve inflection - "step" (figure $2 \mathrm{~b}, \mathrm{c}, t=70 \mathrm{~ns}$ ). The primary current peak at $t<30 \mathrm{~ns}$ ("precursor") is described almost identically by means of both $I_{\mathrm{k}}$ and Sato's current $I_{\mathrm{s}}$ [22] including the charges motion in the discharge volume. As it is seen in figure $2 \mathrm{~b}$, both the "precursor" and the "step" origin is due to $I_{\mathrm{dc}}$ displacement current. The total $I_{\mathrm{k}}$ corona current after $t=100 \mathrm{~ns}$ displays a strong secondary oscillation due to a variable $p$-ions flow to the cathode and namely 

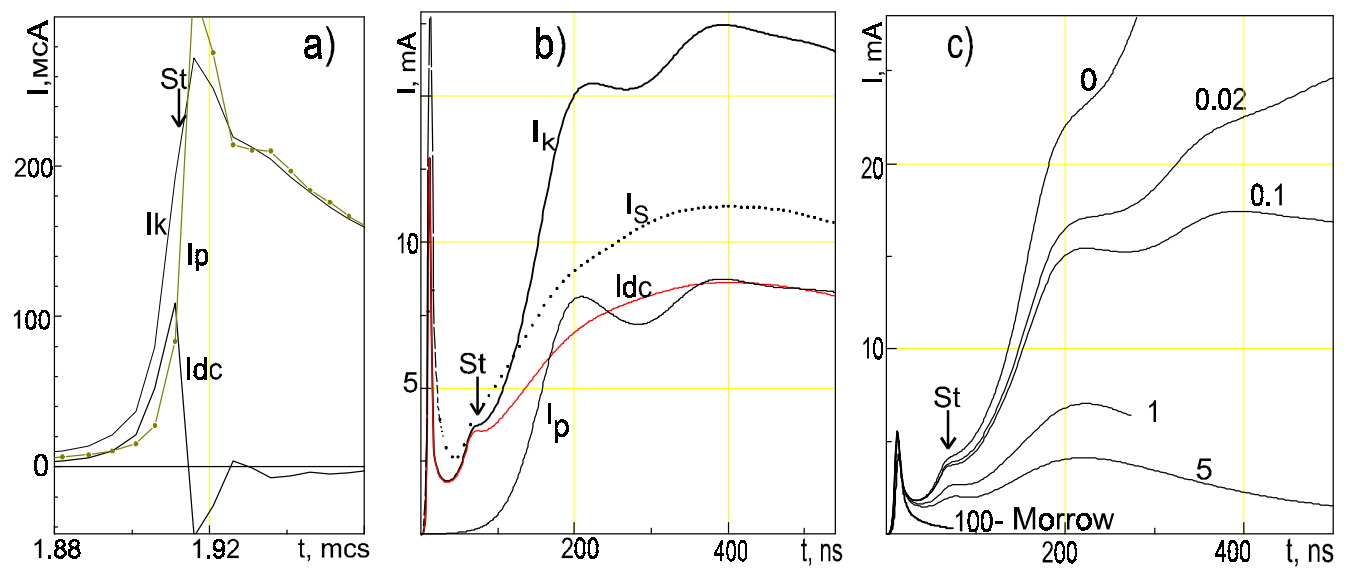

Figure 2. Calculated temporal corona current dependences at the discharge parameters: (a) the edge radius $r_{0}=0.004 \mathrm{~cm}$, the cathode-anode distance $d=0.6 \mathrm{~cm}$, the applied voltage $U=2300 \mathrm{~V}$, the current tube radius in a cathode region $r_{g}=0.006 \mathrm{~cm}$, the generation region length $x_{0}=0.02 \mathrm{~cm}$, the secondary photon-electron emission is absent; $(b, c)$ data [22]. $(a, b)$ the oxygen concentration is $5 \%$; (c) the $\mathrm{O}_{2}$ concentration is variable (the percentages are marked by the numbers).

$I_{\mathrm{p}}$ current results in an increase of the pulse front and the total current oscillation in the following pulse phases, for instance, the secondary maxima at $t=200$ and 380 ns (figure 2b,c). When the secondary photoelectron emission is switched off, the "precursor" height falls down from 16 to $3 \mathrm{~mA}$. This peak disappears when the edge radius is sharply decreased: its height falls to parts of mcA (figure 2a). Extending the modelling [22], the graphs (figure 2c) were obtained. They reflect a gradual transition from the "simple" Morrow's pulse at $100 \% \mathrm{O}_{2}[22]$ to more complicated pulses with the "steps" and the secondary oscillations, which are pronounced at low oxygen concentrations. Evidently, the simulated Morrow's peak [22] is, in fact, the Trichel's pulse "precursor" arising due to the displacement current, caused by ionization processes in the cathode region and at a strong effect of the secondary photoelectron emission from the cathode area, taken unrealistically large for the corona discharge.

\subsection{Corona parameters effect on the characteristics of the secondary cur- rent oscillation}

At certain conditions, the current pulses of negative corona include the secondary current oscillation - a decreasing oscillation or oscillation with the increasing amplitude. Conditionally they can be divided into three types - the peak, the tail and the pre-breakdown ones. The SCO shape strongly depends on the external discharge resistance $R$ (figure 3 and figure 4 ). At the high $R=5 \cdot 10^{6} \mathrm{Ohm}$, this oscillation adopts the shape of the first damping type, which exists in the short time of the order of 2 mcs (figure 3a). Its amplitude decreases when the $\mathrm{O}_{2}$ concentration increases and the pulse shape is similar to the measured ones (figure 1a,b). If the $R$ is 

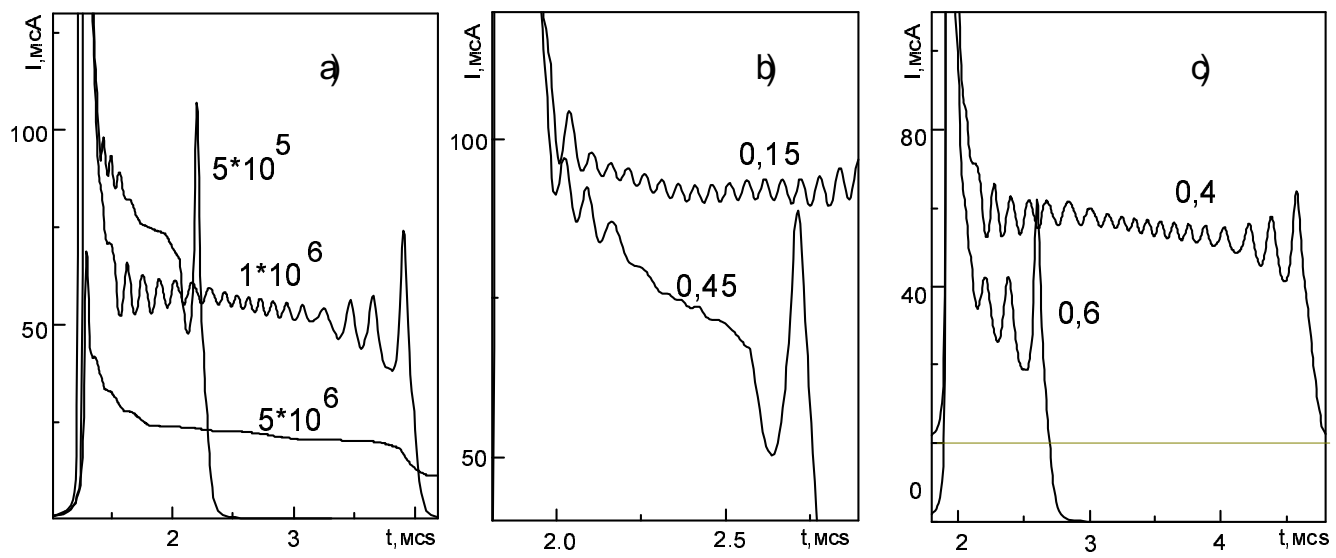

Figure 3. The calculated negative corona pulses with the secondary current oscillation of the first and the second types in $\mathrm{N}_{2}+\mathrm{O}_{2}$ gas mixture, depending on the external resistance (a), and on the oxygen concentration (b, c). The common discharge parameters are the same as in figure 2a. (a) the oxygen concentration $C=0.4 \%$, the external resistance $R$, Ohm, is marked by the numbers; (b) the external resistance $R=5 \cdot 10^{5} \mathrm{Ohm}$, the oxygen concentration, \%, is marked by the numbers; (c) the external resistance $R=1 \cdot 10^{6} \mathrm{Ohm}$, the graphs are shifted along the $y$-axis.

decreased to $1 \cdot 10^{6} \mathrm{Ohm}$, the SCO covers the total peak and tail parts of the pulse (the first and the second types). In the peak part it damps, but at $t=3$ mcs its amplitude increases again. The identical SCO of the second type has been measured in the work [16]. When the resistance is low $\left(R=5 \cdot 10^{5} \mathrm{Ohm}\right)$ and the oxygen concentration decreases to $0.15 \%$ (figure $3 \mathrm{~b}$ ), the oscillation of the second type appears. At the middle resistance $R=1 \cdot 10^{6} \mathrm{Ohm}$ and at a small enough change of the $\mathrm{O}_{2}$ concentration from $0.4 \%$ to $0.6 \%$, the peak SCO damps fully (figure 3c). The secondary "after-pulse" current oscillation of the third type can exist as the damping (figure 4a,b) or with the increasing amplitude (figure 4c), that depends on the resistance value. At the $R$ smaller than of $5 \cdot 10^{3} \mathrm{Ohm}$, the corona pulse transition into the breakdown takes place just after the peak including this type SCO (figure 4c).

\subsection{Clarifying the nature of the corona current secondary oscillation}

Studying the effect of corona parameters on the behaviour of the discharge functions, a strong correlation between the corona current and some values in the generating region (sheath) was discovered. These are the cathode surface field intensity $E_{0}$ (figure 5a), the surface concentration of the positive ions $n_{p 0}$ (figure $5 \mathrm{~b}$ ), the number of the secondary electrons $n_{i e}$ emitted by the cathode under the positive ions impact, the maximal concentration of the positive ions $n_{p m x}$ and electrons $n_{e m x}$, the filling integral $\alpha_{S 1}=\int_{0}^{x_{E m n}} \alpha \mathrm{d} x$ in the region from 0 to the field minimum co-ordinate $x_{E m n}$ (figure $5 \mathrm{c}$ ) and the charges of the positive ions and electrons in the sheath. A shift of the current extrema to shorter times takes place due to the displacement 

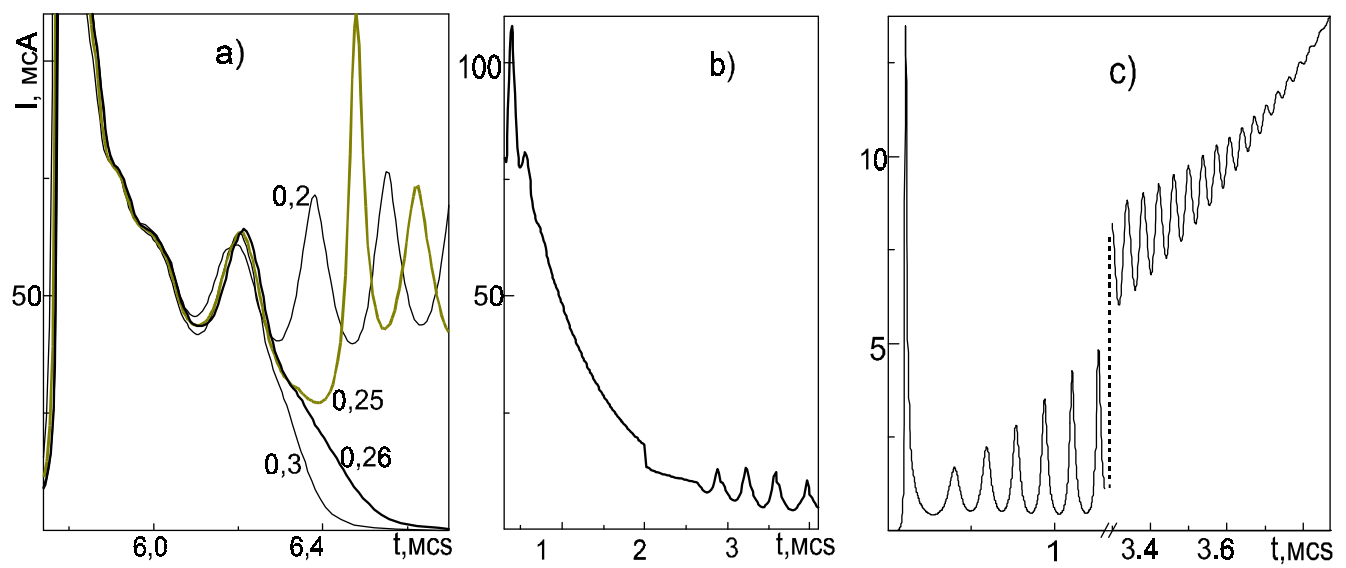

Figure 4. The calculated negative corona pulses with the SCO in $\mathrm{N}_{2}+\mathrm{O}_{2}$ gas mixture at the common discharge parameters: the edge radius $r_{0}=0.004 \mathrm{~cm}$, the cathode-anode distance $d=0.6 \mathrm{~cm}$, the generation region length $x_{0}=0.02 \mathrm{~cm}$, the secondary photon-electron emission is absent: (a) at the external resistance $R=1 \cdot 10^{6} \mathrm{Ohm}$, in a dependence on the oxygen concentration, $C \%$, marked by the numbers, the applied voltage $U=2200 \mathrm{~V}$, the current tube radius in the cathode region $r_{g}=0.006 \mathrm{~cm}$; $(\mathrm{b}, \mathrm{c})$ at the variable current tube radius in the generation region $\left(r_{g 0}=0.003-0.012, r_{g 1}=0.03 \mathrm{~cm}\right)$, (b) $U=1700 \mathrm{~V}, C=5 \%$, $\left.R=5 \cdot 10^{6} \mathrm{Ohm}, \mathrm{c}\right) U=2400 \mathrm{~V}, C=0 \%, R=5 e^{3} \mathrm{Ohm}$.
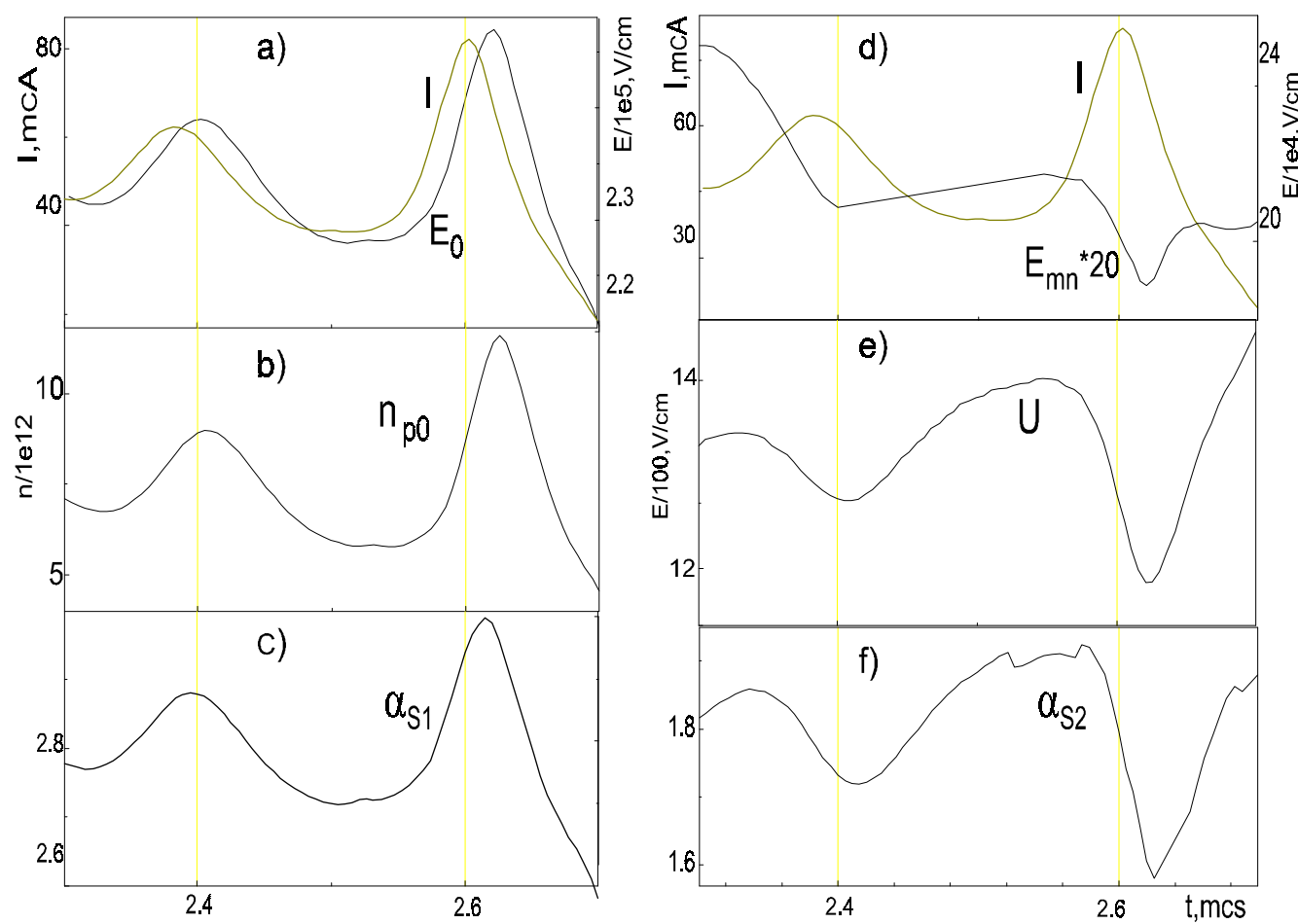

Figure 5. Calculated temporal dependences of the charge and field functions in the corona pulse development, which: $(\mathrm{a}, \mathrm{b}, \mathrm{c})$ are correlated with the secondary current oscillation (calculated at the data given in figure 3c, 0.6\%); (d,e,f) are in an antiphase with SCO. 


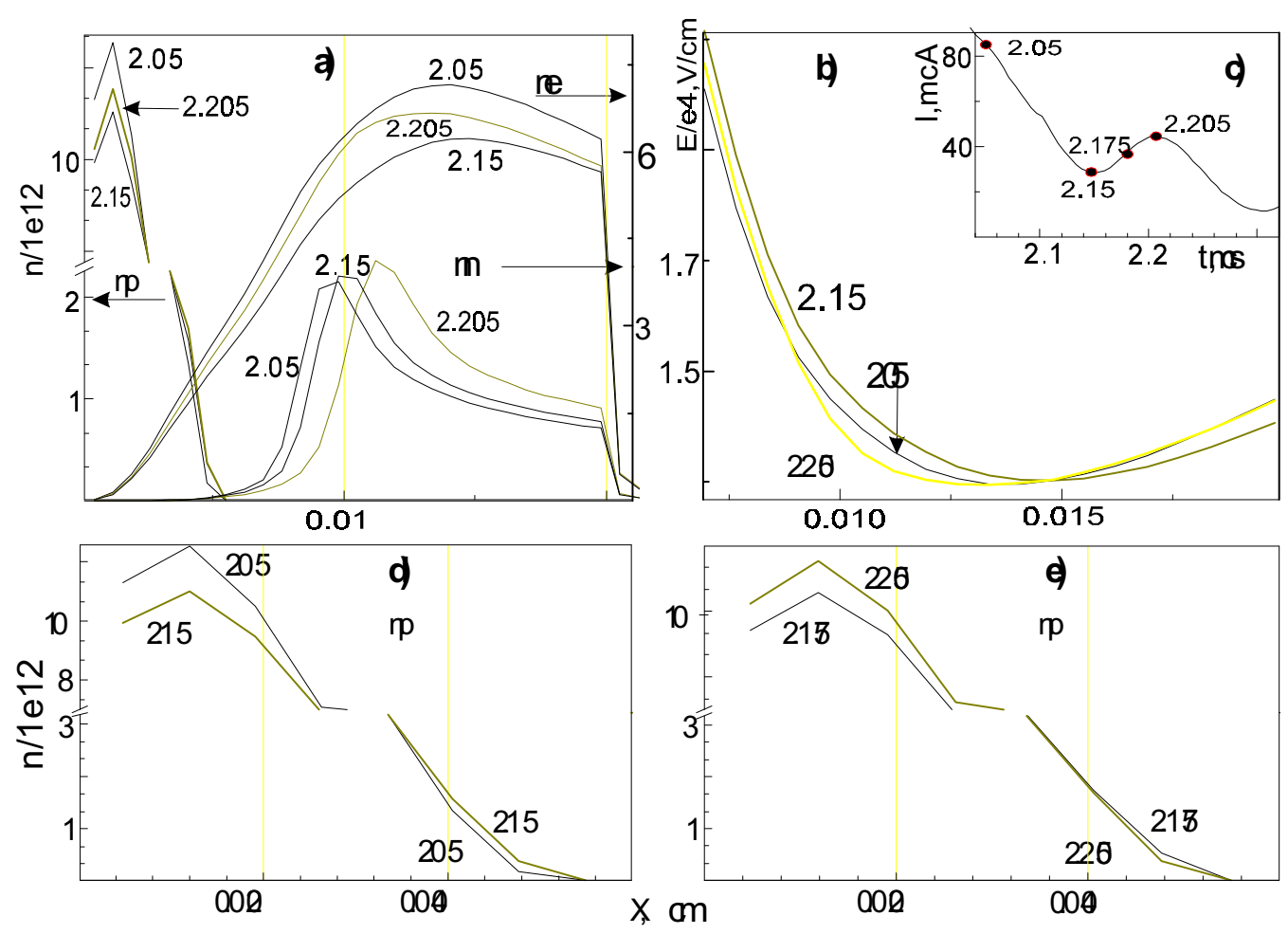

Figure 6. The calculated spatial electron $n_{e}$, positive $n_{p}$ and negative $n_{n}$ ions concentration distributions, (a,d,e), the field intensity $E$ distribution (b) in the corona cathode region, which accord with the typical phases of the secondary current oscillation (c), at the same discharge parameters, as in figure $3 \mathrm{c}, C=$ $0.6 \%$.

current $I_{\mathrm{dc}}$. The integral $\alpha_{S 1}$ depending only on the $E$ intensity changes in phase with the maximal value $E_{0}$, just like the majority of the mentioned values depending on this charge reproduction function. Some plasma functions are in a permanent antiphase with the corona current. These are the field minimum $E_{m n}$ (figure $5 \mathrm{~d}$ ) and its coordinate $x_{E m n}$, the second sheath component of the filling integral $\alpha_{S 2}$ (the range of $x_{E m n} \ldots x_{g}$ ) (figure $5 \mathrm{f}$ ).

Taking into account these correlations one can easily explain the nature of secondary current oscillation. At the moment of the regular current maximum (for example, at $t=2.4 \mathrm{mcs}$, figure 5) under a decrease of the field $E_{m n}$ in the region $x_{E m n} \ldots x_{g}$ the number of the created positive ions decreases. In a half-period of the SCO, these ions will come to the cathode and result in the corresponding current lowering - in its next minimum $(t=2.5 \mathrm{mcs})$. The changes both of the field in the minimum zone and of the co-ordinate $x_{E m n}$ cause a suitable change of the potential differences $U$ in this region, in antiphase to SCO oscillation (figure 5e). At this moment, the total discharge potential fall $U_{\text {cor }}$ practically does not change the amplitude of its oscillation does not exceed $1 \%$. Consequently, it is impossible to discuss the external "trigger" effect on the SCO origin, when in case of the current increase, the resistance voltage increases and the discharge voltage decreases. 
The graphs of the calculated spatial distributions, both the electric field $E$ and the charge concentration $n$ in the sheath in the proper time moments of the SCO (figure 6c), confirm the correlative character of the main discharge functions. Under the condition of the after-peak current decrease (time interval 2.05-2.15 mcs), the ion concentration $n_{p}$ decreases in the cathode region $(0-0.003 \mathrm{~cm})$ and increases in its distribution tail $(0.003-0.006 \mathrm{~cm})$. At the same time, the electron concentration $n_{e}$ decreases in the total generation region $(0-0.02 \mathrm{~cm})$. During the following current increase to the next secondary maximum $(2.205 \mathrm{mcs})$, the reverse processes take place.

\subsection{Photoprocesses effect}

The increase of the near-cathode field (figure $6 \mathrm{~b}$ ) causes the increase of the $\mathrm{N}_{2}$ high levels excitation and the $\mathrm{O}_{2}$ ionization intensities [33,39] during the growth of the pulse front in the $\mathrm{N}_{2}+\mathrm{O}_{2}$ mixture. This photoionization included in the calculation in the full corona gap results in the peak current increase of the same order as the $\mathrm{O}_{2}$ concentration $(0.01-0.04 \%)$. That accords with the almost constant measured current in the inflection region of the pulse $(0.1-0.2 \mathrm{mcs})$ at the concentration of $0.01-0.04 \%$. At the same time, the current increase of the order of $7-10 \%$ has been obtained due to the $\mathrm{N}_{2}$ photoionization in the cathode region $\left(0 \ldots x_{E m n}\right)$. The dependence of the peak part of the current on the $\mathrm{O}_{2}$ concentration (figure 1) has been analysed, taking into account the electron detachment from $\mathrm{O}_{2}^{-}$ion in the $n_{n}$ layer (figure 6a). The collision with the excited nitrogen, the accumulation of $\mathrm{O}_{2}$ molecules and their ionization by some channels [7,26,36-38] were included in the calculation. It appeared that during a few dozens of the pulses, the $\mathrm{O}_{2}$ concentration increases to the percentage units and, consequently, the ionization coefficient of the gas mixture increases proportionally $[7,37]$. The inclusion of the concentration temporal dependence results in the peak current increase of $16.3 \%$ and $123.8 \%$ at the initial concentration of 0.01 and $0.04 \%$, accordingly, that is of the order of the experimental values. The effect of the electron detachment due to the $\mathrm{O}_{2}^{-}$collision with the $\mathrm{N}_{2}\left(\mathrm{~A}_{3} \Sigma_{u}^{+}\right)$metastable $[7,27,38]$ was estimated at the pulse completion stage. The exclusion of this process from the computation results both in the corona current decrease by $27 \%$ and in the pulse duration decrease by $21 \%$ at the 8 th microsecond of the pulse development in $\mathrm{N}_{2}+\mathrm{O}_{2}$ mixture with the oxygen concentration of $0.01 \%$.

\section{Analysis of the results}

The division of the cathode region (generation, sheath) into the zones-layers of the predominantly one type charge placing $(p, n, e)$ (figure 6$)$ is kept during the full pulsation period of the negative corona. That forms both the behaviour of the main plasma functions (figure 5) and the current characteristics in all the pulse stages (figure 2-4). In the initial phases [22], the avalanche charges ( $x$ and $p$ ) reproduction takes place simultaneously with the displacement of the $p$-density maximum to the cathode (figure $3 \mathrm{~b}$ ). At this time, both the $E$-field and the charge reproduction 
coefficient $\alpha$ increase sharply in the region immediately close to the surface, and consequently, the displacement $I_{\mathrm{dc}}$ and the conductivity $I_{\mathrm{p}}$ currents increase sharply (figure 2a). Simultaneously, the field $E$ is essentially reduced behind the layer " $p$ " and consequently, the intensity of the attachment rate increases (it is inversely proportional to $E[22]$ ) and the ion density $n_{n}$ increases (figure $6 \mathrm{a}$ ). As a result, all the undercathode functions $\left(E, \alpha, n_{p}\right.$ etc.) and the currents $I_{\mathrm{dc}}$ and $I_{\mathrm{p}}$ reach the maximal values, controlled by the neighbouring negative ions. Accordingly, when the oxygen concentration in $\mathrm{Ar}+\mathrm{O}_{2}$ rises, the peak current $I_{m}$ decreases (figure 1c). Simultaneously, the decrease of the integral $\int \alpha(x) \mathrm{d} x$ to the critical value is accelerated, hence the pulse duration is shortened (figure $1 \mathrm{a}, \mathrm{b}$ ).

The pulse formation mechanisms in the notions of the Townsend's discharge with the decisive role of the secondary photo- and ion-electron emission $[22,23]$ are denied in the papers $[11,17,21]$. To explain the "step" nature, the comprehension of the "cathode-directed ionization wave" "like streamer" is brought in [11] and the photoelectron emission is substituted by the "ionization wave", as an "alternative to interpretation" of Morrow [21]. In a number of experimental works $[11,16,17]$ the attempts to prove the nature of the "step" were made taking into account the secondary photoelectron emission, and binding the pulse peak with the steamer nature. The results obtained in this paper show (figure 2c) that such "dualisms" in the description of these secondary pule elements is connected with an essential simplifying of the corona geometry by Morrow [22] and with the use of the Sato's expression for the current with the undetailed component of the displacement current (recently the authors have made appropriate corrections [41]). The cathode was set artificially like a sphere with the radius of $0.5 \mathrm{~cm}$ (too large for the corona), the emission area of which is greater in dozens of thousands of such ones in the papers $[11,16,17]$. As a result, a single pulse was calculated (figure 2c, $C$ is equal to $100 \%$ ), mainly for taking into account the essential photoelectron emission. This pulse has turned out to be a "precursor" (mainly invisible) for the measured pulses in many of the following papers $[11,16,17]$. At the essential decrease of the cathode radius [23], two pulse humps were simulated, and the first one was mistakenly explained by the same photoelectron emission. Drawing attention to a full disappearance of the "precursor" at the extremely small cathode radii and making a comparison of the graph figure 1 [23] with the figure 1 of this work, one can affirm that the first hump [23] was caused by the displacement current of the "ionization wave", the photoelectrons did not create the current peak owing to a small emission area and fed up the current with almost constant intensity (see figure 1 [23]). The following maximum $[23]$ is the ion current (figure 1b,c). Thus, the incorrect identification of the first hump- "step" results in the above mentioned superfluous denying the photoelectron effect at a small cathode radius as well as in the incorrect interpretation of the pulse front secondary structures $[11,16,17]$. In our case, the pulse "step" was not experimentally registered in $\mathrm{N}_{2}+\mathrm{O}_{2}$ (figure $1 \mathrm{~b}$ ) because the total ionization rate remains extremely high after the arrival of the positive ions to the surface. This accords with the results of the analysis of the "step" origin in the paper [8]. However, the authors of the [8] associate a completion moment of the "step" forming with a completion 
"of a plasma forming". To our mind, the latter notion is questionable regarding the expressed separation of the charged layers in the cathode sheath (figure 6).

The three simulated types of the secondary current oscillation (the peak, the tail and the pre-breakdown ones) have the characteristics similar to those obtained earlyer experimentally (figure 1), $[3,4,11,16,17]$. Their predominant position depends on the discharge geometry $[2,21]$, on the gas type and on the admixture concentration (figure 1). At a high concentration of electronegative gas, this oscillation can degenerate (figure 1) [11] and is displayed in the form of the "step" and "hump", complicating its interpretation $[11,16,17]$. The SCO is a cause-consequence series of the physical processes of various intensity proceeded in the generation region, specifically: the ionization with the "wave displacement" of its centre - the shielding - the drift - the secondary electron emission etc. The field intensity oscillation in antiphase in the cathode surface region and in the end of the sheath (figure 5a,d) is the external "feedback" of this region, that results in a high-frequency current oscillation. In other words, the SCO is caused by the "negative voltage-current characteristics" of the generation region (figure 5e). The placement of the negative charge layer adjacent to the positive ions layer is a precondition for originating the secondary oscillation $[2,5]$. The excited nitrogen molecules maintain the expanded space between these charged layers (they play a role of the "protector" of the ionization layer). It is confirmed by the secondary oscillation absence in the trailing pulse part in $\mathrm{N}_{2}+\mathrm{O}_{2}$ (figure 1). This oscillation can appear in the current peak region, when the detachment process between the layers just increases. To estimate the duration of this peak part, one has to consider the excited molecules drift time. Owing to the described mechanisms it is easy to explain and to simulate, at some conditions, the SCO on a pulse "tail" $[2,16]$ (figure $4 \mathrm{~b}$ ). This process can transfer into full pulses with the current decreasing to nearly zero values [16], (figure 4c), that is into the Trichel's pulses since their nature is similar. At certain conditions, this high frequency oscillation proceeds to the breakdown (figure 4c).

In the $\mathrm{Ar}+\mathrm{O}_{2}$ mixture, the photoprocesses described for the $\mathrm{N}_{2}+\mathrm{O}_{2}$ are improbable since the intensity of the Ar high levels excitation by electrons of the reduced average energy has low values [7] and the main resonance short wave-lengths 1065.6 and $1048.2 \AA[38]$ are beyond the accessible region of the $\mathrm{O}_{2}$ ionization $(\leqslant 1025 \AA$, [33]). In this gas mixture, the energy losses go mainly for the excitation of the low energy Ar states [7]. At the stage of the pulse completion in $\mathrm{Ar}+\mathrm{O}_{2}$, this causes a dominance of the attachment process. Consequently, the current pulse decreases more steeply, and the absolute current value is considerably lower compared with the ones in $\mathrm{N}_{2}+\mathrm{O}_{2}$ mixture (figure 1).

\section{Conclusions}

1. The shape of the negative corona current pulses with the secondary oscillation and their characteristics in $\mathrm{N}_{2}+\mathrm{O}_{2}$ and $\mathrm{Ar}+\mathrm{O}_{2}$ mixtures are distinctly different. 
2. The main processes of changing the charge state and the photoprocesses in the pulsing corona take place in the cathode region. The decisive process is the formation of different charged layers, the interaction between them and the surface that determines a majority of the pulse characteristics.

3. Secondary current oscillation is caused by the periodic "feedback" interaction of different charged layers in the sheath and the emitting surface. The photoionization and the photodetachment play a significant role. The field intensity oscillation in antiphase in the surface region and in the end of the sheath, as well as the "negative voltage-current characteristics" of the sheath are the causes of the SCO. The pulse secondary oscillation can transfer into the full mode of the Trichel's pulse, since it is of the same nature. Such notions as a "back and forth motion of the electric field" and a "turbulent beam-plasma interaction" are not adequate to this nature.

4. Characteristics of the "precursor" and the "step" in the leading pulse front are determined by the dynamics of the volumetric charges in the generation region, including the secondary emitted electrons. The secondary current oscillation shape is determined by a variable flow of the positive ions to the cathode surface. At a small radius of the cathode, the "precursor" height is negligibly low due to the low photoelectron emission while the "step" duration is very short due to an extremely high speed of "ionization wave" in the increasing under-surface electric field.

5. Corona current pulse shape in the nitrogen-oxygen mixture in the peak part is formed by the ionization of the accumulated oxygen molecules in the cathode region. In the argon-oxygen mixture such a process is weakened due to the lowered energy of the electrons.

6. The effect of the electron detachment from $\mathrm{O}_{2}^{-}$by the metastables on the current value and on the pulse duration is distinctly different in the nitrogen and argon mixtures.

\section{References}

1. Trichel G.W. // Phys. Rev., 1938, vol. 54, p. 1078-1084.

2. Chyhin V. // SU "Lviv Polytechnika" Bulletin. Electronics, 2000, No. 397, p. 136-146.

3. Chyhin V., Omelchuk O. // SU "Lviv Polytechnika" Bulletin, 1996, No. 304, p. 88.

4. Chyhin V., Skulsky M. // NU "Lviv Polytechnika" Bulletin. Electronics, 2001, No. 423, p. $131-141$.

5. Chyhin V. - In: Intern. Symposium HAKONE VII, Greifswald, 2000, p. 18-22.

6. Sigmond R.S. - In: Electrical Breakdown of Gases. Wiley, 1978, p. 358.

7. Raizer Yu. Gas Discharge Physics. M., 1987.

8. Gupta D., Mahajan S., John P. // J. Phys. D, 2000, p. 681-691.

9. Chyhin V., Fedoryshyn O., Skulsky M. // SU "Lviv Polytech." Bull. Electronics, 1999, No. 382 , p. $50-56$. 
10. Cross A., Morrow R., Haddad G. // J. Phys. I, 1986, vol. 19, p. 1007-1017.

11. Cernak M., Hosokawa T. // Phys. Rev. A., 1991, vol. 43, p. 1107-1109.

12. Scott D.A., Haddad G.N. // J. Phys. D: Appl. Phys., 1987, vol. 20, p. 1039-1044.

13. Ikuta N., Kondo K. // IEE Conf. Publ., 1976, vol. 143, p. 227.

14. Chyhin V., Rudavski Yu. - In: Intern. Conference XXY ICPIG, Nagoya, 2001, vol. 4, p. $17-18$.

15. Chyhin V., Rudavski Yu. - In: Intern. Symposium ISPC-15, Orlean, 2001, vol. 8, p. 3187-3192.

16. Zahoranova A., Cernak M. - In: 12th Symp. Appl. Plasma Procs. SAPP-12, Slovakia, 1999, p. 250-251.

17. Zahoranova A., Cernak M., Wagner H. // Czech. J. Phys., 1999, vol. 49, No. 12, p. $1721-1735$.

18. Chyhin V. Generator of relaxing oscillation. Ukraine Patent No. 25169A, 1998.

19. Chyhin V. Electrofilter. Ukraine Patent No. 22211, 1998.

20. Akishev Ju., Napartovich A. // Letters to JETPh, 1996, vol. 22, p. 1-6.

21. Napartovich A., Akishev Ju. // J. Phys. D: Appl. Phys., vol. 30, 1997, p. 2726-2736.

22. Morrow R. // Phys. Rev. A., 1985, vol. 32, No. 3, p. 1799-1809.

23. Morrow R. // Phys. Rev. A., 1985, vol. 32, No. 6, p. 3821-3824.

24. Cernak M. - In: Intern. Confer. XXII ICPIG, 1995, p. 136.

25. Chyhin V., Boiko O. // SU "Lviv Polytechnika" Bulletin, 1998, No. 337, p. 283-286.

26. Aleksandrov N., Napartovich A. // Teplophys. Vysok. Temper., 1981, vol. 19, No. 3, p. 485-490.

27. Akishev Yu., Napartovich A. // Plasma Physics, 1994, vol. 20, No. 6, p. 571-584.

28. McDaniel I. Collision Processes in Ionizated Gases. 1967.

29. Morrow R. // J. Phys. D., 1997, vol. 30, p. 3099-3114.

30. Ranjan A., Goodyear F. // J. Phys., Mol. Phys., 1973, vol. 6, p. 1070-1077.

31. Wynn M., Martin J. // J. Chem. Phys., 1970, vol. 52, p. 191-203.

32. Kossyi I. et al. // Plasma Sources Sci. Technol., 1992, vol. 1, p. 207-220.

33. Zheleznjak T., Mnacakanyan A. // Teplophys. Vysok. Temper., 1981, vol. 20, No. 3, p. $423-428$.

34. Hartmann G., Gallimberti I. // J. Phys. D, 1975, vol. 8, p. 670-680.

35. Jelenkovic V., Phelps A. // Phys. Rev. A., 1987, vol. 36, No. 11, p. 5310-5326.

36. Eichwald O., Yousfi M. et al. // J. Appl. Phys., 1997, vol. 82, No. 10, p. 4781-4794.

37. Guerra V., Pinheiro M., Loureiro J. // Plasma Sources Sci. Technol., 1997, vol. 6, p. 220-230.

38. Smirnov B. Ions and Excited Atoms, 1974.

39. Penney G., Hummer G. // J. Appl. Phys., 1970, vol. 41, No. 2, p. 572-577.

40. Belashi A., Boeuf J., Pitchford L. // J. Appl. Phys., 1993, vol. 74, No. 3, p. 1553-1567.

41. Morrow R., Sato N. // J. Phys. D, 1999, vol. 32, p. 1.20-1.22.

42. Sigmond R.S. Gas Discharge Data Sets for Dry Oxygen and Air. N-7034. TrondheimNTH, Norway, 1979 (partly revised - 1983).

43. Smirnov B.M. Negative Ions. Moscow, Atomizdat, 1978 (in Russian).

44. Parkes A. // Vacuum, 1974, vol. 24, No. 11, p. 561-571.

45. Morrow R., Lowke J. // J. Phys. D, 1997, vol. 30, p. 614-627.

46. Van Brunt R., Kulkarni S. // Phys. Rev., 1990, vol. 42, No. 8, p. 4908-4932.

47. Van Brunt R. // IEEE Trans. Electr. Insulat., 1991, vol. 26, No. 5, p. 902-948.

48. Gallimberti I., Hepworth J. // J. Phys. D, 1974, vol. 7, p. 880-898. 
49. Smirnov B.M. Excited Atoms. Moscow, Atomizdat, 1982 (in Russian).

50. Physical Bases of Electric Breakdown of Gases. Ed. Dyakov A., Moscow, MEI Publ., 1999 (in Russian).

51. McDaniel I., Mason E. Mobility and Diffusion of Ions in Gases. Moscow, Mir, 1976 (in Russian).

52. Hasted J. Physics of Atomic Collisions. Moscow, Mir, 1965 (in Russian).

\title{
Фізичні механізми Формування імпульсів струму від'ємної корони із вторинною структурою
}

\author{
В.І.Чигінь \\ Національний університет "Львівська політехніка",
} 79013 Львів, вул. С.Бандери, 12

Отримано 9 жовтня 2001 р., в остаточному вигляді - 21 січня $2002 \mathrm{p}$.

Проведено детальне моделювання нерівноважних процесів у від'ємному коронному розряді, зокрема, імпульсів струму із вторинними осциляціями (BOC) на основі числового розв'язання рівнянь неперервності для позитивних і негативних іонів та електронів, разом із рівнянням Пуассона для електричного поля в квазі-одномірному просторі. Проаналізовано поведінку основних функцій плазми пульсуючої корони у сумішах аргону з киснем та азоту з киснем в області концентрацій $2 \cdot 10^{-3} \%-0.04 \%$, що дало змогу вперше обгрунтувати фізичні механізми зародження і розвитку ВОС. Виявлено, що три типи ВОС можуть існувати у різних часових інтервалах імпульсу. Встановлено, що вони є результатом коливання в антифазі напруженості поля в приповерхневій області та в кінці прикатодної оболонки. Характеристики "прекусора" і "сходинки" на провідному фронті імпульсу визначаються динамікою об'ємних зарядів в оболонці, тоді як форма ВОС задається змінним потоком позитивних іонів на катод. Додатково, вперше оцінено впливи фотопроцесів на параметри різко відмінних імпульсів у досліджених сумішах газів. В $\mathrm{N}_{2}+\mathrm{O}_{2}$ іонізація молекул $\mathrm{O}_{2}$ фотонами, емітованими збудженими молекулами $\mathrm{N}_{2}^{*}$ приводить до адекватного росту пікового струму. Тривалість і значення струму у хвостовій частині імпульсу задається зіткненнями іонів $\mathrm{O}_{2}^{-}$із метастабілями $\mathrm{N}_{2}^{*}$. У суміші $\mathrm{Ar}+\mathrm{O}_{2}$ такі процеси $є$ слабими.

Ключові слова: коронний розряд, імпульс струму, тонка структура імпульсу, вторинні осциляції струму, фотопроцеси, числове моделювання

PACS: $52.80 . H c, 52.35 .-g, 52.65 .-y, 51.50 .+v$ 